\title{
PALATE: THE APP FOR FINDING A RESTAURANT FASTER
}

by

Patrick Gioseffi

Bachelor of Arts, Honors Specialization in Media, Information, and Technoculture (MIT)

London, Ontario, Canada, 2016.

\author{
A MRP \\ presented to Ryerson University \\ in partial fulfillment of the \\ requirements for the degree of \\ Master of Digital Media \\ in the program of Digital Media
}

Toronto, Ontario, Canada, 2019

(C) Patrick Gioseffi, 2019 


\section{AUTHOR'S DECLARATION FOR ELECTRONIC SUBMISSION OF A MRP}

I hereby declare that I am the sole author of this MRP. This is a true copy of the MRP, including any required final revisions.

I authorize Ryerson University to lend this MRP to other institutions or individuals for the purpose of scholarly research.

I further authorize Ryerson University to reproduce this MRP by photocopying or by other means, in total or in part, at the request of other institutions or individuals for the purpose of scholarly research.

I understand that my MRP may be made electronically available to the public. 


\title{
PALATE: THE APP FOR FINDING A RESTAURANT FASTER
}

Master of Digital Media, 2019

Patrick Gioseffi

Master of Digital Media, Ryerson University

\begin{abstract}
This Major Research Project (MRP) aims to investigate the impact of the on-demand economy, millennials' digital habits, and the emergence of super apps on the restaurant-finding process. Currently, restaurant-goers are presented with multiple specialty applications to complete different tasks when evaluating restaurants. The current process of deciding on a restaurant is both time-consuming and inefficient. This project aims to propose a solution to this problem in the form of an early-stage super app called Palate. Palate is a mobile application that aims to streamline the process of discovering restaurants from the moment a restaurant-goer begins their search to the moment they confirm a reservation. This paper will discuss design principles, theories of the on-demand economy, restaurant-goers digital habits, super apps and the rationale for designing a restaurant super app interface.
\end{abstract}




\section{Acknowledgements}

I would like to thank Vishal Badiani and Meg Tyrell for their endless amount of guidance, support, and encouragement both during the MDM program and while preparing this MRP. I'm grateful for them both being incredibly generous with their time and insight. It is thanks to them that this MRP has come to fruition. 


\section{Table of Contents}

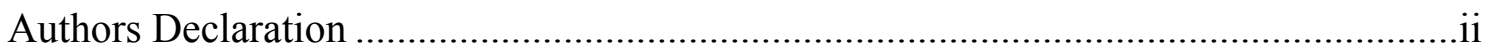

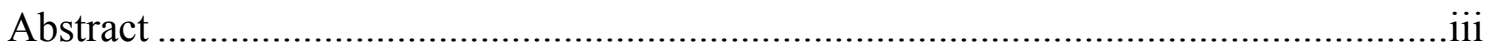

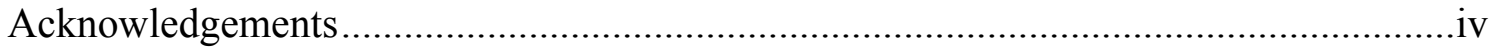

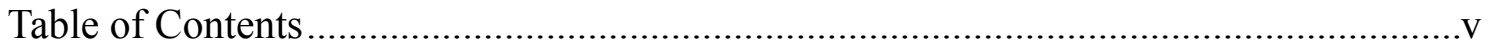

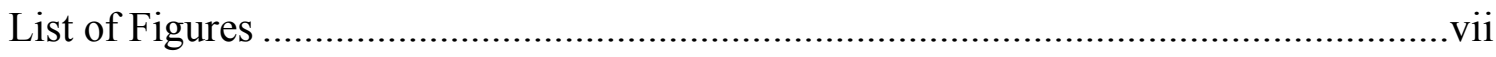

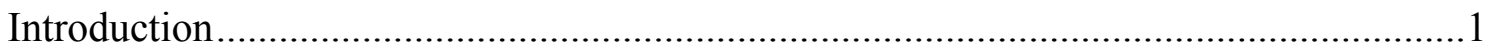

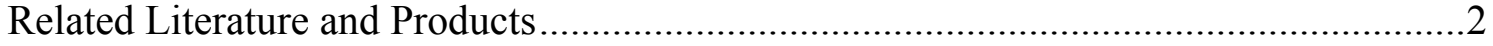

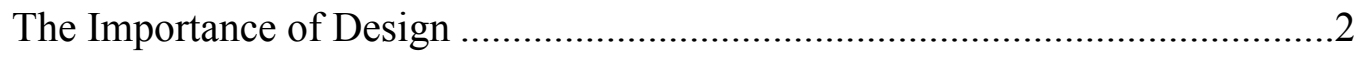

Dieter Rams and good design ........................................................2

Don Norman on design ................................................................. 3

Design and accessibility ............................................................

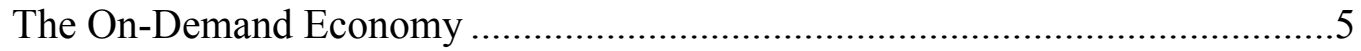

Restaurants, Apps, and Consumers' Digital Habits ......................................6

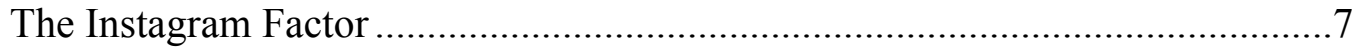

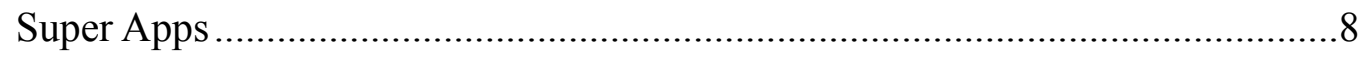

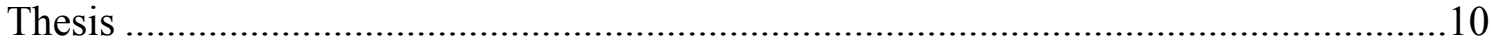

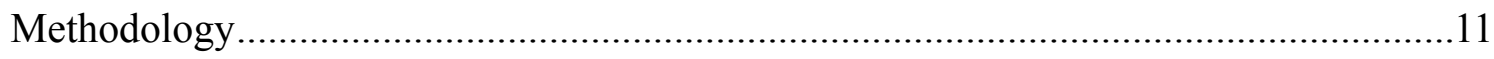

The Target Audience: Millennials ............................................................11

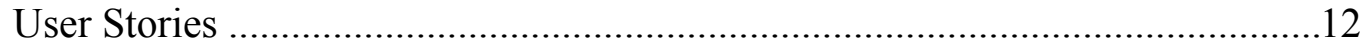

Current Platforms Available in the Restaurant-Finding Process ...........12

Restaurant Finding Process - Usability Study....................................13

Proposed Restaurant Finding Process with Palate ..............................13

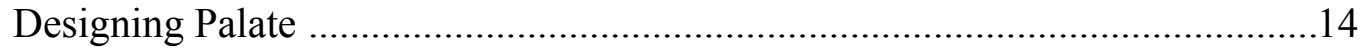

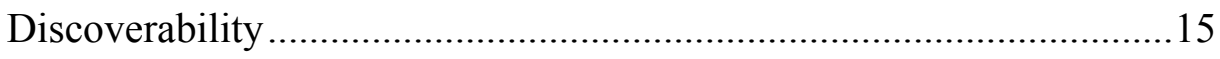

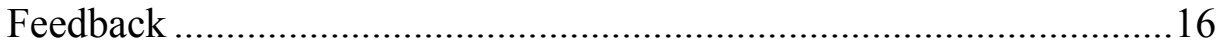

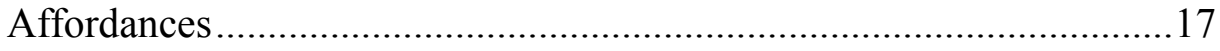

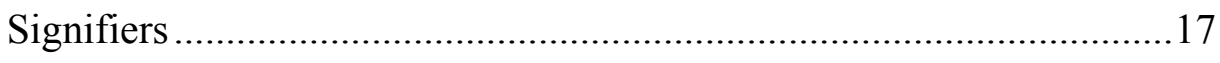

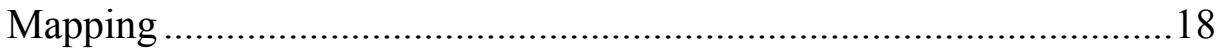




\section{Table of Contents Continued}

Conceptual Models ....................................................................... 18

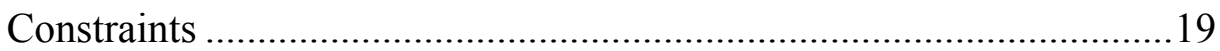

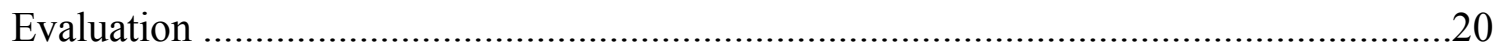

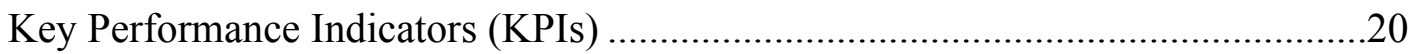

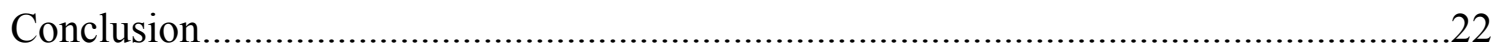

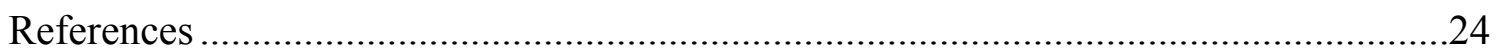




\section{List of Figures}

Figure

Page

1 Current Platforms Available in the Restaurant-Finding Process .....................12

2 Proposed Restaurant Finding Process for Palate ..........................................14 
Palate: The App for Finding a Restaurant Faster

\section{Introduction}

According to a survey conducted by OpenTable, " $56 \%$ of consumers said they were 'very unlikely' or 'unlikely' to download an app for an individual restaurant" (Jennings, 2015). In fact, survey respondents indicated preference towards apps that collect various pieces of information from multiple restaurants (Jennings, 2015). The current landscape of the restaurant industry presents users with multiple digital applications and websites to use when choosing where to eat. The problem is that many restaurant discovery applications do not integrate with third-party services in a way that maximizes efficiencies for the end user. As a result, there is a need for a single app that will enable users to complete all necessary tasks. A proposed solution is an app called Palate.

This paper will discuss design principles, the on-demand economy, consumers' digital habits, and the emergence of super apps to provide insight into why a better solution is both possible and needed. This paper will then explore Palate's design to demonstrate the rationale for its proposed user interface. 


\section{Related Literature and Products}

\section{The Importance of Design}

Design plays a crucial role in any digital and physical product. The principles outlined by design experts Dieter Rams and Don Norman are necessary to consider for the proposed restaurant-finding application, Palate. Although Dieter Rams' work in the later half of the 20th century involved physical products including but not limited to radios, shavers, clocks, and record players, his principles are equally as important when designing digital products such as the solution presented in this major research project (Rawsthorn, 2011).

Dieter Rams and good design. For Dieter Rams, good design is as follows (Rams, 2012):

1. Innovative - design should improve as technology improves

2. Makes a Product Useful

3. Aesthetic

4. Makes a Product Understandable

5. Unobtrusive

6. Honest

7. Long-Lasting

8. Thorough to the Last Detail

9. Environmentally Friendly

10. As Little Design as Possible — good design should focus on the essential 'aspects' 
Similarly, researcher and design expert Don Norman defines fundamental principles of interaction which contribute to pleasurable experiences for users.

Don Norman on design. Don Norman's seven fundamental principles of design are (Norman, 2013, p. 10-30):

- Discoverability

- Feedback

- Affordances

- Signifiers

- Mappings

- Conceptual Models

- Constraints

Discoverability enables users to figure out what actions are possible with an object. (Norman, 2013, p. 72). Discoverability is achieved through the remaining design principles described. Feedback is an element used to communicate with a user that an action has been taken. The light that is often emitted from an elevator button once pushed is an example of feedback. Affordances refer "to the relationship between a physical object and a person" (Norman, 2013, p. 11). The term is used to describe what an object will allow a person (or user) to do with it. For example, a chair affords the ability for someone to sit on it. Signifiers, whether intentional or unintentional, communicate purpose, structure, and operation. For instance, left and right arrows on a website's photo gallery page communicate that more photos are available by clicking in either direction. Mappings refer to the relationship between one control (or button) and another element of the object (or interface). A clear example of mapping 
is a room full of multiple lights and a lighting panel that is laid out in a manner that makes it easier for the user to understand which switch corresponds to which light (Norman, 2013, p. 11-25). Conceptual Models are simplified communication tools to indicate how something works. Folders on a computer are an example of how conceptual models are used to explain how information is stored for the user. Constraints refer to signs that indicate what actions an object is limited to - this can include physical, cultural, semantic, or logical constraints. An example of a constraint is the physical shape and positive \& negative indicators of a battery which explain the only orientation permitted for that object to work properly (Norman, 2013, p. 125).

Like Dieter Rams, Don Norman's focus is not on digital products; however, his principles are most noticeable in everyday products that are used, including his most notable example, socalled 'Norman doors'. 'Norman doors' refer to various confusing doors that Don Norman has interacted with and experienced difficulty determining how they should open; especially when their form goes against logical thinking. For example, some doors with a handle are actually push doors. Moreover, some sliding doors retract upwards. The variety and confusion of a simple, everyday object demonstrates the importance of good design in products (Norman, 2013, p. 1). Combined, the principles defined by both Dieter Rams and Don Norman create a framework for good design which will be used to inform the digital design interface of Palate.

Design and accessibility. In addition to Dieter Rams' and Don Norman's work that provide a framework for the digital design interface of Palate, accessibility guidelines and best practices are also essential to consider. According to a report issued by the World Bank, one in seven people around the world are living with some form of disability (World Bank, 2019). The needs of these 1 billion people must be taken into account when designing both physical and 
digital environments. The World Wide Web Consortium (W3C), an organization led by the inventor of the web, Tim Berners Lee, has created standards and guidelines abiding by their principle of creating a "web for all" (W3C, 2019-a).

W3C's four principles of accessibility define that web content must be: perceivable, operable, understandable, and robust. Perceivable refers to the fact that web content must be capable of being presented to users without ignoring all of the users' senses. Operable refers to the standard that the interface's components and navigation must allow for the user to take action. Understandable refers to the fact that the information and interface should be easily understood. The robust principle defines that content must be capable of being interpreted as both user abilities and technologies evolve (W3C, 2019-b). These four principles will guide both the design and future technical development of Palate.

\section{The On-Demand Economy}

The on-demand economy refers to "digital platforms that connect consumers to a service or commodity through the use of a mobile application or website" (Cockayne, 2016, p. 73). Platforms like these often enable consumers to instantly reserve, pay for, receive (or a combination of all three) a service or commodity using their internet-connected device. Popular examples of platforms within the on-demand economy include Uber \& Lyft (ride-hailing services), Airbnb (accommodation booking service), and OpenTable (restaurant reservation service). The platforms mentioned are arguably the leaders in their respective on-demand industries. It is worth nothing that there are many other companies working in this growing field to support the demand. According to a 2015 study, the U.S. on-demand economy is attracting 22.4 million consumers annually; a number that is reportedly growing particularly among 
millennials. The term 'millennials' refers to individuals born between the years of 1981 and 1996 (Pew Research Centre, 2018). With this demand from consumers, many industries are being impacted including the restaurant and food industry. In fact, $\$ 4.6$ billion were spent on food and grocery-related on-demand services in the U.S. in 2015 (Colby \& Bell, 2017). Research suggests that this trend will continue to grow and therefore may require products or services to continue to meet these consumer demands.

\section{Restaurants, Apps, and Consumers' Digital Habits}

Consumers are increasingly reliant on mobile applications within the restaurant industry. Using survey data collected by OpenTable and information collected via interviews with executives from Starbucks, Panera, and BJ's Restaurants, Lisa Jennings' work reveals the ways by which digital technology — specifically mobile applications — have shaped consumer habits. The survey data suggests that, "56 percent of consumers said they were 'very unlikely' or 'unlikely' to download an app for an individual restaurant." Instead, consumers prefer one app that collects information from many restaurants (Jennings, 2015). Despite this preference, restaurants are building out their mobile offerings to improve the customer experience including the ability to order and pay ahead. However, uptake among consumers has been slow. Jennings' work revealed that even the leader in food-related mobile innovation, Starbucks, only saw about $20 \%$ of its weekly transactions originate from mobile ordering (Jennings, 2015). Her findings suggest that aggregators may very well be the answer to rapid uptake among consumers. Current restaurant-related apps that collect information from many sources include Yelp, TripAdvisor, Google Reviews, and OpenTable. However, individually, these apps still only allow their users to complete a fraction of the tasks needed when evaluating and selecting a restaurant. 
Yelp and TripAdvisor enable users to search for restaurants while displaying user reviews, prices, and links to external menus (TripAdvisor, 2019; Yelp, 2019). Following an acquisition of SeatMe in 2015, Yelp also offers its own in-house reservation system called Yelp Reservations (Bertram, 2019). Google reviews, a feature embedded within Google's search results acts as an aggregator of information providing Google users' reviews, a link to an external menu, and a link to a third-party reservation website, if applicable (Google, n.d.). OpenTable provides the same restaurant information as Yelp, TripAdvisor, and Google Reviews; however, it also enables users to instantly make a reservation at partner restaurants (OpenTable, 2019).

Integrations and partnerships with other apps and technologies have become methods for restaurant-finding platforms to differentiate themselves among competition and improve the customer experience. For example, Yelp's acquisition of both SeatMe and Turnstyle Analytics have been integral to their offerings (Bertram, 2019). Furthermore, OpenTable and Instagram began partnering in 2018 to offer a 'Reserve' button on applicable restaurant Instagram profiles (OpenTable, 2018). The ongoing efforts of restaurant-related platforms adding integrations in order to gain and maintain a competitive advantage suggests that there are still features missing to truly create a seamless experience for restaurant-goers.

\section{The Instagram Factor}

Instagram is a social media platform that boasts 1 billion monthly active users (Constine, 2018). The photo-sharing platform is particularly popular among millennials — the same age group of people who are the most likely generation to eat at restaurants instead of at home (Oyedele, 2018, Pew Research Center, 2019). Although reviews are important to consider when choosing a restaurant, Instagram is essential to the restaurant-finding process. The platform has 
become a hub for restaurants to promote their offerings and restaurant-goers to learn about them. In fact, a UK survey found that millennials spend five days a year browsing food images on Instagram to determine which restaurants they will visit (Hosie, 2017). Instagram's tagging features contribute to the time spent deciding as it enables users to click on other users' photos to see which restaurant (or general location) it was taken. This allows a user to post a photo of a restaurant, tag the restaurant (geotag or official account), and enables the user's Instagram followers to learn key pieces of information including: the restaurant name, location, and what the food/atmosphere is like (Instagram, 2019). It is an opportunity for restaurants to gain potential customers or at least capture their interest using photos. Research has indicated that a restaurant's aesthetic has a direct effect on a customer's satisfaction (Jin et al, 2019). Restaurants have become cognizant of this influence and have begun to plan their business models and interior design around how 'Instagrammable' they are (Newton, 2017). The motivation stems from appealing to potential customers on Instagram as well as satisfying restaurant-goers. In addition to individual apps that collect information from multiple restaurants, Instagram is pivotal in the restaurant-finding process.

\section{Super Apps}

With the increasing rise and success of 'super apps' in the Asian mobile market, North American consumers may also expect and benefit from these integrations. Super apps are mobile applications that bundle numerous services together creating a seamless experience for users without the need to open specialty apps (Schaal, 2019). With Asia's innovative super apps, users can, "communicate, shop online, order rides, read books, play games, get food delivery..." and pay for goods within a single app (Lee, 2018). The most telling examples of the appeal and 
demand for these types of apps is seen with apps WeChat, Grab, and Go-Jek. WeChat attracts more than a billion users each month while Grab and Go-Jek were reported by Bloomberg as Asia's most valuable startups (Lee, 2018). The large number of users downloading these apps suggests that these products are meeting a consumer demand for multiple integrations in one single interface. 


\section{Thesis}

"The rise of the on-demand economy, millennials' habits, and the growing success of super apps suggests a gap in the restaurant-finding process. Palate is the proposed solution to fulfill this need and create a seamless and efficient experience for users in the form of an early-stage super app."

With disjointed pieces of information in the restaurant industry, restaurant-goers are presented with specialty apps and websites for individual tasks. Yelp, TripAdvisor, and Google provide restaurant reviews. Individual restaurant websites are often the source for menus. Moreover, Instagram provides users with crowd-sourced, high-quality images of both restaurant interiors and dishes. Platforms including and similar to OpenTable enable restaurant-goers to instantly make reservations using their device. Google Maps provides an in-depth navigation system for users to get to their destination. This process of switching between multiple apps is inefficient. For this major research project, a prototype for a mobile app and service, Palate, has been created to demonstrate how an early-stage super app could speed up the restaurant-finding process specifically among North American millennials. 


\section{Methodology}

\section{The Target Audience: Millennials}

Statistics Canada (2019) data indicates that millennials are the largest generation in Canada. The word 'millennials' refers to individuals born between the years of 1981 and 1996 (Pew Research Centre, 2018). This particular age group, compared to previous generations, are reported to be delaying marriage and having children. The delay in major milestones such as these enable millennials to spend a greater amount of their income on dining out (Couillard, 2019). They are also reportedly the most likely group to eat at restaurants instead of at home (Oyedele, 2018). Millennials' density in the market, their dining habits, along with their growing position within the large number of on-demand economy users indicate that this generation is an ideal group for adopting the digital product presented in this MRP. Despite the product's suitability for any individual looking for a new restaurant, millennials are the target audience for Palate as the goal is to achieve rapid uptake from this generation in the form of early adopters. In the technology industry, the phrase 'early adopters' refers to individuals who are the first to use a new product before others. They are often willing to pay more (with their time or money) for a new product if it means creating efficiencies, reducing costs, or improving their social status (Investopedia, 2018). Palate's end goal is to create efficiencies in the restaurant-finding process in the form of a digital product. 


\section{User Stories}

To illustrate the opportunities for reducing friction for users and creating efficiencies, a user story of a restaurant finding process is presented. User stories originate from the agile method of software development where a product is broken down into its smaller parts for easier understanding and implementation of user needs. User stories provide insight into who the feature is for, what is expected, and why it is important (Lucassen et al, 2015). Figure 1 and Figure 2 describe the third-party app (if applicable) that may be currently used to achieve restaurant-related tasks.

Current platforms available in the restaurant-finding process. In Figure 1, each grey box represents a task while the white boxes indicate the currently available websites or apps that may be used to achieve the task. Each dashed line indicates the need of switching to a different mobile application or website. These are the opportunities for efficiencies.

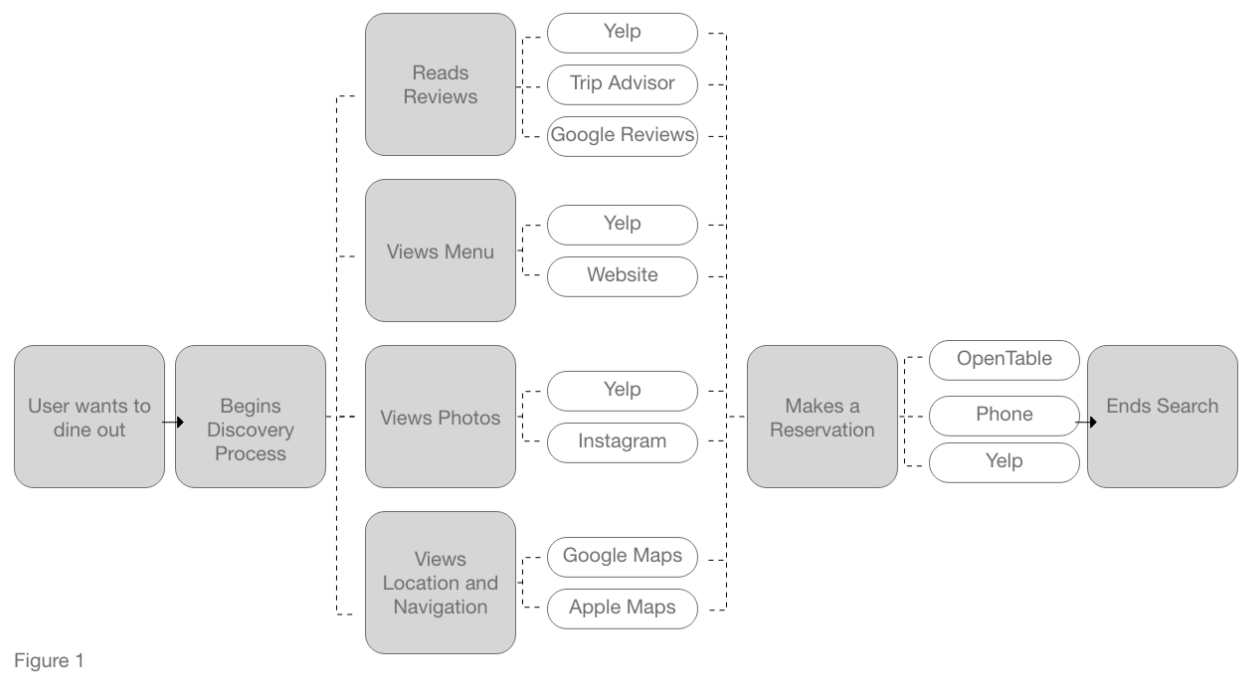

Figure 1. Current Platforms Available in the Restaurant-Finding Process 
Restaurant finding process - usability study. In order to test if Palate may meet the need of being a seamless app for restaurant-goers, three peers from my Ryerson University User Experience (UX) for Digital Products class were consulted in a usability study to describe how they currently discover and evaluate restaurants. One peer indicated that they currently use Yelp, Trip Advisor, and Google Reviews to evaluate restaurants. The same user noted that they use multiple apps at once for this task. A second peer noted that they experience difficulties with existing platforms including Yelp and Google Reviews; also reporting that they use a combination of both services to browse restaurants. Moreover, a third peer reported using a combination of Yelp, Google Reviews, OpenTable, and personal recommendations when resolving the difficulties presented in the restaurant-finding process (Gioseffi, personal communication, January 2019). Using the current platforms available user story and the information provided by peers, a proposed user story for Palate users has been created.

Proposed restaurant-finding process with Palate. In Figure 2, a user story is presented on how a user may benefit from the features and integrations within Palate. Similarly to Figure 1, dashed lines represent a different mobile application that is needed to achieve the task. In comparison, only one additional app, the native phone call feature on the device, would be needed to achieve the task while using Palate whereas the current process presents nine different required applications to switch between (see Figure 1). 


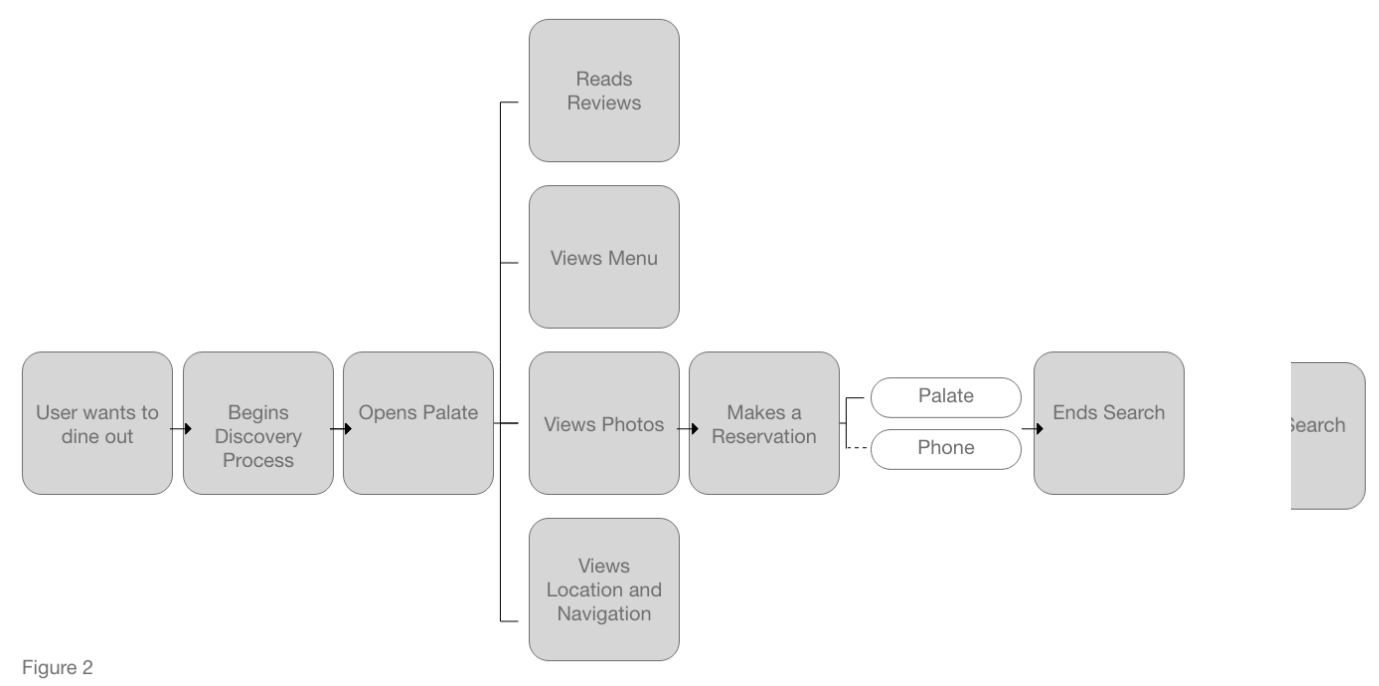

Figure 2. Proposed Restaurant Finding Process for Palate.

\section{Designing Palate}

The 'good design' indicators as defined by Dieter Rams along with the fundamental principles of design outlined by Don Norman were essential to the design process of Palate. As a proposed super app, a mobile application to create a seamless restaurant-finding experience for users, Dieter Rams' principles provide a sound framework on how to create an innovative, useful, and aesthetically-pleasing product. The design process began by digitally wireframing each of the stages described in the proposed user story for Palate users. Wireframing is an important step as it creates a low-fidelity version of an interface ensuring that all major features, content, and elements are considered early into the design process (Usability.gov, n.d.). The focused approach to wireframing also relates to one of Dieter Rams' (2012) design principles stating that good design is as little design as possible; it prevents the possibility of many unnecessary features being added. Furthermore, Rams' principle defining that good design makes a product useful was also specifically crucial during the wireframing stage (Rams, 2012). It 
created an internal guideline that all features included in the wireframes must be essential to creating a useful experience for the end user. While Dieter Rams' work informed the wireframing strategy of Palate's product goals, Don Norman's seven fundamental principles of design provided a reference for how users would interact with the high-fidelity version of the product and its features where colour, content, and interaction were included.

Discoverability. As previously mentioned, Discoverability refers to how a user determines what actions are possible with an object (Norman, 2013, p. 72). While designing the interface of Palate, three elements were crucial to consider in order to create a highly discoverable product: Navigation, Flow, and Context. As a super app, presumably filled with multiple features and screens, a clear and simple navigation was needed to guide the user throughout the restaurant-finding process. After reviewing best practices from other social networking sites and on-demand economy service apps including Instagram, Uber, Airbnb, Yelp, TripAdvisor and OpenTable, it became apparent that all had five-button navigation bars. The exceptions were TripAdvisor which contained four buttons and OpenTable which had three buttons. Instagram's navigation consists of a home, search, post, notifications, and profile button (Instagram 2019). Uber's navigation contains a button for your trips, payment, help, free rides, and settings (Uber Technologies, 2019). Airbnb's navigation included a button for explore, saved, trips, inbox, and profile (Airbnb, 2019). Yelp's contained a button for search, activity, me, collections, and more (Yelp, 2019). TripAdvisor's navigation included a button for home, trips, inbox, and me (TripAdvisor, 2019). OpenTable's especially focused navigation included the following buttons: home, search, reservations (OpenTable, 2019). This prompted close consideration as it meant Palate's navigation may also need to be focused. As an early-stage 
super app with the intention of combining multiple functionalities, it became clear that a three or four-button navigation section would be unrealistic. As a result, a five-button navigation section was created with the following titles: Explore, Saved, Reservations, Popular, Profile — an amalgamation of the navigations presented in the previously mentioned apps.

Guided by the proposed Palate user story, it was also important that the app's features and possible actions were presented in a manner that matched the flow of the user's journey. Context was also a key piece to creating a highly discoverable product. Using the flow of the app, context guided the stages of which certain actions were available to users. For example, photos of a restaurant's aesthetic are only shown to a user when they have expressed interest in the restaurant by clicking on it. Navigation, flow, and context were implemented using the additional six fundamentals of design as outlined below.

Feedback. According to Don Norman, feedback refers to the process of an action occurring on an object and its new state being communicated back to the user (Norman, 2013, p. 72). For an on-demand economy app, being able to quickly and clearly communicate feedback is important from a design perspective. For Palate, colour is used as the main method of providing feedback to the user to communicate that an action has occurred; specifically on a single screen when a state has changed. For example, when a user is browsing restaurants and taps on an icon to add it to their saved list of restaurants, the save button (a heart icon) changes colour from a white heart with a blue outline to a solid blue heart. Furthermore, when a user goes through a multi-step process on a single screen, specifically when making a restaurant reservation, button colours change from a lighter colour to a darker one to indicate that the button has been previously selected. In addition to using colour to provide feedback, the speed of the interaction 
was also also considered as it was paramount that the feedback was immediate (Norman, 2013, p. 24).

Affordances. Visible and perceived affordances are used throughout Palate to indicate how users can interact with the product. Affordances were included in Palate based on the goals included in the proposed user story (see Figure 2). The affordances that were given priority are as follows:

- Search for a restaurant based on location (Perceived)

- Read reviews (Visible)

- View menus (Visible)

- View photos (Visible)

- Make a reservation (Visible)

However, as Don Norman notes, affordances are indicated by signifiers, another fundamental design principle (Norman, 2013, p. 72). The following section explains how and which signifiers are used within Palate to communicate both perceived and visible affordances.

Signifiers. Signifiers in the form of symbols and text were implemented to communicate what actions are possible within the Palate interface. For instance, on each restaurant's screen, there are three key pieces of information available: reviews, photos, and menu. Although, for aesthetic purposes, it is preferred to only incorporate perceived affordances by using symbols alone, this may leave room for error on the user's understanding of the affordance. To mitigate the possibility of the user misunderstanding the product and its capabilities, a combination of both symbols and text were used. For each restaurant's three pieces of information (reviews, photos, and menu), text and symbols were used. In addition to the respective word, reviews 
included a star icon, photos included an image icon, and menu included an icon of an open, folded piece of paper. For accessibility purposes, alt-text will also be included for each icon in the app's development stage.

Mapping. As a location-based app, mapping is used within Palate to indicate what information belongs to which restaurant. Similar to the use of colour within the app to provide feedback, colour was also implemented to communicate the relationship between information. For instance, when a user is browsing available restaurants near them on a map, multiple location pins are shown. A single black location pin shown indicates the selected restaurant whereas the numerous blue pins indicates the possible restaurants that can be selected and explored. In order to communicate the relationship between the selected restaurant (the black pin) and the restaurant information shown on screen, the consistent use of black text is included to show that the two pieces of information are connected.

Conceptual Models. The implementation of conceptual models also contribute to a highly discoverable and intuitive digital product. To reiterate, conceptual models simplify seemingly complex processes (Norman, 2013, p. 25). With the goal of being an early-stage super app, Palate provides users with information from multiple data sources which may create confusion as to who is facilitating the interaction. One instance of a feature included is the integration of a third-party reservation service, OpenTable. Although Palate, from a technical perspective, does not create the reservation nor store it, the navigation item 'Reservations' enables users to select and review both their past and upcoming reservations. This feature creates a seamless experience as the backend integration of multiple services is intentionally hidden from the user for easy use. 
Constraints. In order to create an easy-to-use digital product, constraints are used to assist users in their flow throughout the app. Although there are four types of constraints: physical, cultural, semantic, and logical, cultural constraints are the primary constraint used throughout Palate (Norman, 2013, p. 125). Due to the product's target demographic, the millennial, cultural constraints are implemented to guide users on what data is available. For example, as research indicated within the literature review, millennials are turning to Instagram photos to influence their restaurant decision making process. Therefore, Palate does not enable users to view photos from other sources other than Instagram as it is seemingly part of the millennial culture. This cultural constraint not only limits action but also strategically narrows the product's audience for the purpose of generating early adopters of the service.

Furthermore, the app's information architecture presents constraints. As the interface could have taken many different forms, its current design includes constraints that were unintentionally created during the process. As a new app, it presents restrictions in what users are permitted to do. For example, currently, there is very little social functionality within the app. However, this could change in the future. Using both user testing results as well as analytics information captured once in the market, constraints can be lessened by both testing and implementing future product features. A proposed feature may be allowing users to follow celebrities within Palate to see what restaurants they are dining at — something that is currently not enabled within the app 


\section{Evaluation}

With the uptake in on-demand services and technologies, companies must meet consumer demands by demonstrating the benefit of their platforms (Colby \& Bell, 2017). Currently, individual apps are used in effort to aid restaurant-goers in the mobile-first era. However, these apps rely on customers' willingness to switch between apps when in fact consumers have a preferences towards downloading only a single app (Jennings, 2015). The design of Palate ensures that restaurant-goers no longer need to leave or navigate through multiple apps. Instead, all necessary features are packaged into one convenient app. The features and services used in other restaurant-finding, navigation, and social media applications have been carefully considered and included in the design of the app with the intent of allowing users to find a restaurant faster. The success of Asia's billion dollar super apps that consumers use to manage daily tasks and services suggest the increasing demand for seamlessly integrated mobile applications. Despite efforts by existing restaurant-finding apps, no service is attempting to completely solve user pain-points from start to finish like Palate. Instead, current evaluation suggests that many are focusing on specialty apps to create efficiencies in a single process rather than considering the user's story as a whole. In order to determine and monitor Palate's success, key performance indicators (KPIs) will be used once the app has been developed and used by restaurant-goers.

\section{Key Performance Indicators (KPIs)}

As an early-stage super app, Palate's usage is essential to understand its competitiveness in the mobile app market. The following KPI categories will be first implemented and measured to determine Palate's performance and how it can be improved: acquisition metrics and 
engagement metrics. Acquisition metrics will measure the number of restaurant-goer sign ups along with the flow of their interactions within the app. For instance, understanding the point at which restaurant-goers become uninterested in the on-boarding process will inform the app's future strategy. Engagement metrics will measure how many in-app interactions occurred per user. For example, the number of users who used the location-based search, saved feature, reservation service, trending page, and profile section will all be tracked to determine which features are the most or least popular among users. 


\section{Conclusion}

Through the use of Dieter Rams principles of design along with Don Norman's fundamentals, a prototype for Palate was created to demonstrate the efficiencies that can be made in the restaurant-finding process - specifically in response to the increasingly growing ondemand economy and millennials' digital habits. While anticipating the rise of super apps in North America, Palate's design positions itself as a potential leader to streamline a user's experience from the initial search to the reservation confirmation stage. The seamless experience is enabled by integrating existing services and data sources into the single platform.

Although efforts have been made to design an intuitive product in keeping with design principles and best practices, further usability testing is needed before moving into the development stage; especially to ensure compliancy with accessibility standards and legislature. As indicated in this paper, the app's design was carefully created using best practices from other on-demand economy industry leaders; however it is possible following user testing that it may change both from a feature, design, or interface perspective entirely. Future work into the relation between the on-demand economy and accessibility may be beneficial to understand how the needs of those with disabilities can be met using innovative technologies, services, and commodities.

Future research would be useful in the area of what particular data sources are available, how they would be technically implemented, and how time-sensitive information could be handled. For instance, the frequency of restaurants updating their menus would need to be considered to discover how Palate's content could remain both timely, accurate, and therefore 
competitive. Furthermore, future work and inquiry is needed in the area of how apps similar to Palate may generate revenue while relying on third-party integrations and data.

Although this early-stage super app aims to ultimately benefit the end user, there is a possibility of risks that may be of concern. Specifically, super apps and privacy may be a future domain of study due to the often data-rich nature of such platforms. More broadly, the Asian mobile market, its culture, and the ways by which it has enabled successful super apps is key for future work to understand user motivations and predict similar apps' success. 


\section{References}

Airbnb. (2019). Airbnb (Version 19.20) [Mobile application software]. Retrieved from https:// itunes.apple.com/

Bertram, C. (2019, February 26). Yelp Grabs More Restaurant Reservations in OpenTable Challenge. Retrieved from https://www.bloomberg.com/news/articles/2019-02-26/yelp$\underline{\text { takes-larger-bite-out-of-restaurant-reservation-market }}$

Cockayne, D. G. (2016). Sharing and neoliberal discourse: The economic function of sharing in the digital on-demand economy. Geoforum, 77, 73-82. doi:10.1016/j.geoforum. 2016.10.005

Colby, C., \& Bell, K. (2017, October 05). The On-Demand Economy Is Growing, and Not Just for the Young and Wealthy. Retrieved from https://hbr.org/2016/04/the-on-demandeconomy-is-growing-and-not-just-for-the-young-and-wealthy

Constine, J. (2018, June 20). Instagram hits 1 billion monthly users, up from 800M in September. Retrieved from https://techcrunch.com/2018/06/20/instagram-1-billion-users/

Couillard, L. (2019). Full-Service Restaurants in Canada. IBISWorld Industry Report 72211CA. Retrieved from IBISWorld database.

Dirks, J. (2019, January 27). 6 in 10 millennials using third-party food delivery apps: Study. Retrieved from https://www.ctvnews.ca/business/6-in-10-millennials-using-third-partyfood-delivery-apps-study-1.4270496

Ferreira-Marques, C. (2019, January 02). Superapps will starve the rest in Southeast Asia. Retrieved from https://www.reuters.com/article/us-grab-gojek-breakingviews/ breakingviews-superapps-will-starve-the-rest-in-southeast-asia-idUSKCN1OW02F

Gioseffi, P. (2019, January). Personal communication. 
Google. (n.d.). Google [Website]. Retrieved from www.google.com

Haggin, P. (2016, September 20). Allset Raises $\$ 2.35 \mathrm{M}$ to Speed Up Restaurant Lunches.

Retrieved from https://www.wsj.com/articles/allset-raises-2-35m-to-speed-up-restaurantlunches-1474383600

Hosie, R. (2017, April 11). Millennials spend five entire days every year looking at food on Instagram. Retrieved from https://www.independent.co.uk/life-style/food-and-drink/ millenials-restaurant-how-choose-instagram-social-media-where-eat-a7677786.html

Instagram. (2019). Instagram (Version 93.0) [Mobile application software]. Retrieved from https://itunes.apple.com/

Investopedia (2018). Market and Economy Insights: Early Adopter. Retrieved from https:// www.investopedia.com/terms/e/early-adopter.asp

Jennings, L. (2015). Restaurants seek new ways to meet consumers' high expectations for mobile features. Nation's Restaurant News, 49(15), 22-27. Retrieved July 24, 2019.

Jin, N. (., Merkebu, J., \& Line, N. D. (2019). The examination of the relationship between experiential value and price fairness in consumers' dining experience. Journal of Foodservice Business Research, 22(2), 150-166. doi:10.1080/15378020.2019.1592652

Lee, Y. (2018, November 7). Super Apps, Asia's New Innovation, to Change Cities, Economies. Retrieved from https://www.bloomberg.com/news/articles/2018-11-07/super-apps-asias-new-innovation-to-change-cities-economies

Lucassen, G., Dalpiaz, F., Martijn E. M. Van Der Werf, J., \& Brinkkemper, S. (2016). Improving agile requirements: The Quality User Story framework and tool. Requirements Engineering, 21(3), 383-403. doi:10.1007/s00766-016-0250-x 
Newton, C. (2017, July 20). How Instagram is reshaping restaurant design. Retrieved from https://www.theverge.com/2017/7/20/16000552/instagram-restaurant-interior-designphoto-friendly-media-noche

Norman, D. (2013). The Design of Everyday Things: Revised and Expanded Edition. New York: Basic Books.

OpenTable. (2019). OpenTable (Version 12.16) [Mobile application software]. Retrieved from https://itunes.apple.com/

OpenTable. (2018). OpenTable Integration Arrives on Instagram: Diners Can Now Book a Table via Your Profile. Retrieved from https://openforbusiness.opentable.com/tips/technology/ opentable-integration-arrives-on-instagram-diners-can-now-book-a-table-via-yourprofile/

Oyedele, A. (2018, March 04). Millennials' eating habits are wildly different from their parents' and the food industry has to face urgent consequences. Retrieved from https:// www.businessinsider.com/how-millennials-eating-habits-differ-from-babyboomers-2018-3

Panko, R. (2018, July 10). The Popularity of Google Maps: Trends in Navigation Apps in 2018. Retrieved from https://themanifest.com/app-development/popularity-google-mapstrends-navigation-apps-2018

Pew Research Centre. (2018). Defining Generations. Retrieved from https://www.pewresearch.org/fact-tank/2018/04/11/millennials-largest-generationus-labor-force/ft_18-04-02 generationsdefined2017_working-age/

Pew Research Centre. (2019). Share of U.S. adults using social media, including Facebook, is mostly unchanged since 2018. Retrieved from https://www.pewresearch.org/fact-tank/ 
2019/04/10/share-of-u-s-adults-using-social-media-including-facebook-is-mostlyunchanged-since-2018/ft_18-04-02_generationsdefined2017_working-age/

Ponnappa, S. (2019, February 11). What is a 'Super App'? Retrieved from https://

blog.gojekengineering.com/what-is-a-super-app-4f2d889451e6

Rams, D. (2012). Dieter Rams: Design by Vitsœ [PDF]. New York: Vitsœ.

Rawsthorn, A. (2011, June 06). How Dieter Rams Made Braun Look Cool. Retrieved from https://www.nytimes.com/2011/06/06/arts/design/how-dieter-rams-made-braun-an-itbrand.html

Russell, J. (2015, June 30). Mangoplate, Korea's Answer To Yelp, Lands \$6.1M And Eyes Expansions Across Asia - TechCrunch. Retrieved from https://techcrunch.com/ 2015/06/30/mangoplate-plates-up-6-1-million/

Schaal, D. (2019, April 22). Google Maps Is Ready to Transform the World of Superapps: A Skift Deep Dive. Retrieved from https://skift.com/2019/04/16/google-maps-is-ready-totransform-the-world-of-superapps-a-skift-deep-dive/

Statistics Canada. (2019). Wealth and debt. How are millennials doing?. [Infographic] Retrieved from https://www150.statcan.gc.ca/n1/pub/11-627-m/11-627-m2019029-eng.htm

TripAdvisor. (2019). TripAdvisor. Retrieved from https://www.tripadvisor.ca/

Uber Technologies. (2019). Uber (Version 3.351.10003) [Mobile application software].

Retrieved from https://itunes.apple.com/

Usability.gov. (n.d.) Wireframing. Retrieved from: https://www.usability.gov/how-to-and-tools/ methods/wireframing.html

W3C. (2019-a). About W3C. Retrieved from https://www.w3.org/Consortium/

W3C. (2019-b). Introduction to Understanding WCAG 2.0. Retrieved from https://www.w3.org/ TR/UNDERSTANDING-WCAG20/intro.html 
World Bank. (2019) Disability Inclusion. Retrieved from https://www.worldbank.org/en/topic/ disability

Yelp. (2019). Yelp (Version 12.35.2) [Mobile application software]. Retrieved from https:// itunes.apple.com/ 